DOI: $\underline{\text { https://doi.org/10.24867/07BE30Bozic }}$

\title{
PRIMENA PID REGULATORA U STABILIZACIJI I UPRAVLJANJU KRETANJEM KVADKOPTERA
}

\section{APPLICATION OF PID REGULATORS IN STABILIZATION AND MOTION CONTROL OF QUADCOPTER}

\author{
Milan Božić, Fakultet tehničkih nauka, Novi Sad
}

\begin{abstract}
Oblast - ELEKTROTEHNIKA I RAČUNARSTVO
Kratak sadržaj - U radu je prikazan jedan od načina implementacije letelice na daljinsko upravljanje kvadkoptera za čije upravljanje se koristi STM32F103C8T6 kontroler, za određivanje položaja letelice koristi se inercijalni senzor IMU MPU9250 (akcelerometar $i$ žiroskop) dok se za aktuatore koriste motori bez četkica. Senzorski i aktuatorski deo povezuje tri PID regulatora koji su implementirani u kontroleru. Upravljanje se vrši radio vezom na $2.4 \mathrm{GHz}$ modulom za komunikaciju NRF24l01. Letelica obezbeđuje podatke o temperaturi, vlažnosti $i$ atmosferskom pritisku uz pomoć senzora BME280.
\end{abstract}

Ključne reči: dron, kvadkopter, akcelerometar, žiroskop, PID, BME280, NRF24L01, MPU6050, MPU9250, STM32

\begin{abstract}
The paper presents one of the ways of implementing a remote control aircraft - a quadcopter whose STM32F103C8T6 controller is used, to determine the position of the aircraft using an inertial IMU MPU9250 sensor (accelerometer and gyroscope) while brushless motors are used for actuators. The sensor and actuator part connects the three PID controllers implemented in the controller. It is controlled by radio communication on the $2.4 \mathrm{GHz}$ communication module NRF24101. The aircraft provides temperature, humidity and atmospheric pressure data using a BME280 sensor.
\end{abstract}

Keywords: drone, quadcopter, accelerometer, gyroscope, PID, BME280, NRF24L01, MPU6050, MPU9250, STM32

\section{UVOD}

Veoma često je u praksi za rešavanje različitih zadataka potrebno da letelice imaju mogućnost vertikalnog poletanja i sletanja. Dronovi su u ovoj oblasti nenadmašni. Kvadkopteri predstavljaju podvrstu letelica na daljnsko upravljanje koji se odlikuju osobinom da sadrže četri uzgonska motora čijim se upravljanjem vrši kretanje letelice. Danas se kvadkopteri nalaze u različitim aspektima života, od vojne industrije do industrije zabave. Različiti zadaci zahtevaju različite performanse. Na primer, u vojnoj industriji potrebno je da letelica bude pouzdana

\section{NAPOMENA:}

Ovaj rad proistekao je iz master rada čiji mentor je bio dr Vladimir Rajs, docent. i robustna i da predstavlja sistem otporan na otkaze, dok je u industriji zabave potrebno da letelica ima što bolje dinamičke osobine - da može da napravi različite akrobatske pokrete i da bude što atraktivnija i zabavnija. I jednu i drugu vrstu letelica povezuju zajednički zahtevi za senzorima i aktuatorima, s tom razlikom što je negde potrebno koristiti senzor veće pouzdanosti i rezolucije merenja, negde je potrebno koristiti motore sa jačim potiskom.

Ovaj rad će proći kroz sve potrebne segmente za izradu ove vrste letelice dajući opšte šeme kao i postulate koje je potrebno koristiti kako bi se postigli što bolji rezultati leta. Akcenat se stavlja na implementaciju PID (eng. proportional-integral-derivative) algoritma za stabilizaciju i kretanje kvadkoptera. Izrađeni kvadkopter predstavlja niskobudžetnu letelicu sa radijusom kretanja do $1 \mathrm{~km}$. Letelica nema implementiran algoritam za stabilizaciju visine (eng. auto leveling).

\section{ALGORITAM SENZORA MPU9250 ( MPU6050 )}

Za upravljanje letelicom pre svega potrebno je dobro izvršiti čitanje trenutnog položaja. Ovo se vrši kombinacijom senzora akcelerometra i žiroskopa. U ovom radu korišćen je devetoosni senzorski sistem sastavljen od troosnog akcelerometra, troosnog žiroskopa i troosnog magnetometra. U projektu nije bilo potrebe za korišćenjem magnetometra. Korišćeni senzor MPU9250 sastavljen je od dva senzora MPU6050 i AK8963, akcelerometar + žiroskop i magnetometar, redom. Kako magnetometar nije korišćen algoritam koji će biti predstavljen potpuno će odgovarati i senzoru MPU6050 kao i MPU6500 koji predstavlja unapređenu generaciju $I M U$ senzora.

Apsolutni položaj letelice bi se mogao odrediti samo uz pomoć akcelerometra kada bi se vibracije koje proizvode motori i propeleri svele na zanemarljive. Kako je akcelerometar veoma osetljiv na vibracije njegov izlaz je potrebno filtrirati niskopropusnim filtrom $i$ tada njegov signal zbog kašnjenja koje filtar unosi postaje neupotrebljiv za upravljanje letelicom u realnom vremenu.

$\mathrm{Na}$ slici 1 dat je prikaz izlaza akcelerometra pri vibracijama proizvedenim od strane rotora. Takodje vidimo da je dugoročno gledano signal konzistentan, ali kao što je već rečeno potrebno ga je filtrirati i nije ga moguće koristiti za kontrolisanje letelice $\mathrm{u}$ realnom vremenu. 
Bitno je naglasiti da signal akcelerometra nema promene vrednosti u stanju mirovanja (eng. drift) tokom vremena i iz tog razloga je veoma bitan za ove vrste letelica.

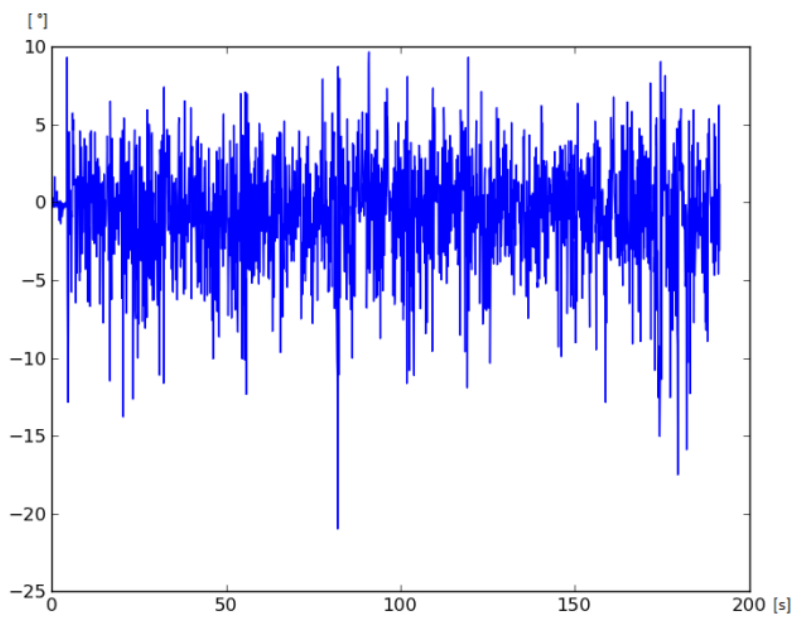

Slika 1. Odziv akcelerometra uz vibracije rotora [1]

Žiroskop kao senzor koji ima mogućnost da detektuje brzinu kretanja ovde ga možemo iskorisititi da bismo prikupili sva kretanja i što preciznije odredili trenutni položaj senzora, a samim tim i letelice. Problem koji se neminovno javlja kod žiroskopa je šum koji se sjedinjava sa signalom. Kombinacija akcelerometra i žiroskopa daju senzor koji je moguće korisititi za stabilizaciju letelice.

Na slici 2 data je blok šema algoritma koji je potrebno implementirati za pravilno korišćenje žiroskopa i akcelerometra.

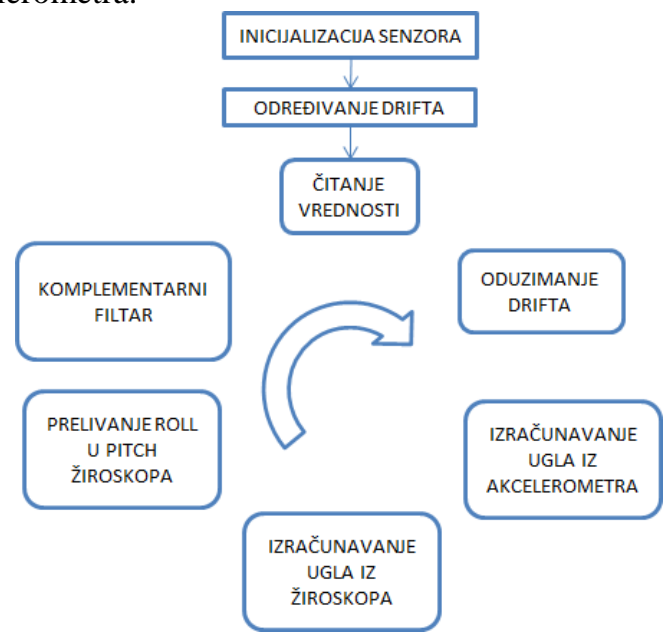

Slika 2. Algoritam za odredjivanje ugla iz ziroskopa $i$ akcelerometra

Pod iniclijalizacijom senzora podrazumeva se: podešavanje njegove rezolucije, mogućnost određivanja semplovanja kao i testiranja ispravnosti senzora. Oduzimanje drifta žiroskopa podrazumeva sabiranje određenog broja odbiraka kada senzor miruje zatim deljenje sa brojem odbiraka. Ova dva koraka se izvršavaju pri uključivanju senzora i nakon toga se ciklično smenjuju ostali koraci.

Prvi u seriji koraka je da se pročitaju vrednosti iz senzora, zatim je potrebno oduzeti predhodno određenu vrednost za neutralisanje šuma što predstavlja naredni korak. Kada su podaci pročitani moguće je odrediti uglove iz akcelerometra i žiroskopa što su naredna dva koraka. Naredni korak ima zadatak da pri rotaciji letelice oko Z ose vrši prelivanje roll-a u pitch i obrnuto u zavisnosti od sinusa ugla rotacije. Nakon što su uglovi pravilno izračunati da bi se dugotrajno osiguralo merenje bez šuma dodaje se komplementarni filtar koji uzima $1 \%$ vrednosti izračunatih u akcelerometru i 99\% vrednosti iz žiroskopa. Ovaj ciklus čitanja potrebno je vršiti što češće kako bi merenje bilo što preciznije, u praksi je dovoljno izračunavati brže od $250 \mathrm{~Hz}$ [2]. U realizovanom sistemu, ciklus se odvija brzinom od $500 \mathrm{~Hz}$.

\section{PID REGULATOR}

Za stabilizaciju letelice korišćen je $P I D$ kontroler po tri ose rotacije. Dva identična $P I D$-a po roll i pitch i još jedan kontroler po yaw [3].

U nastavu je dat korišćeni $P I D$ regulator.

$\mathrm{P}=\operatorname{koefP} *$ error

$\mathrm{I}+=$ koefI $*$ error

$\mathrm{D}=$ koefD $*($ delta_error[0]+delta_error[1]+delta_error[2])

$\mathrm{PID}=\mathrm{P}+\mathrm{I}+\mathrm{D}$

- koefP, koefI i koefD predstavljaju koeficijente regulatora koje je potrebno podesiti.

- error predstavlja trenutnu grešku,

- delta_error predstavlja poslednje tri razlike error-a. Možemo reći da daje informaciju o napredovanju greške.

D regulator razlikuje se od klasičnog D regulatora iz razloga što prikuplja informacije i o prethodnim delta error-ima. Prednost ovog pristupa je što ako se javi lažna greška zbog vibracija akcelerometra ona će u velikoj meri biti potisnuta od sledeće dve delta greške. Ovaj pristup smanjuje vibracije koje se dobijaju od nesavršenosti senzora.

Koeficijenti koji daju najbolje rezultate su :

koefP $=0.52$, koefD $=15.5$, koefI $=0.001$

Dati koeficijenti daju najbolje rezultate za izrađeni model i nece imati najbolje rezultate na nekom dugom hardveru ali se mogu koristiti kao startni koeficijenti sa podešavanje stabilizacije.

U izrađenoj letelici koristi se laserski senzor udaljenosti ToF (eng. TimeOfFlight) VL53L01 kako bi se odredila udaljenost od podloge. Ako se detektuje da se letelica nalazi na zemlji tada se iskuljučuje I regulator - ovim se povećava brzina stabilizacije letelice jer se sprečava nekontrolisan rast I regulatora dok se letelica ne odvoji od zemlje.

\section{KOMUNIKACIJA}

Komunikacija između upravljačke jedinice (eng. joystick) i letelice ostvarena je uz pomoć komunikacijonog modula NRF24L01. Ovaj primo-predajnik obezbeđuje razmenu informacija između leteice i upravljača u oba smera, za upravljanje letom upravljački signali šalju se od upravljača ka letelici dok se u suprotnom smeru šalju informacije o bateriji, trenutnoj visini , pritisku vazduha , temperaturi i vlažnosti vazduha.

Poruke koje se razmenjuju su veličine 8 bajta. U nastavku su date tabele podataka koji se razmenjuju. 
Tabela 1. Raspored podataka ( upr. jed. - letelica )

\begin{tabular}{|c|c|c|c|c|c|c|c|}
\hline 0 & 1 & 2 & 3 & 4 & 5 & 6 & 7 \\
\hline UD & LR & FB & Rot & Cam & CamON & non & non \\
\hline
\end{tabular}

UD - Opšta brzina svih motora

LR - Skretanje po Roll-u

FB - Skretanje po Pitch-u

Rot - Rotacija

Cam - Pomeranje kamere

CamON - Uključivanje kamere

non - Nekoristi se

Tabela 2. Raspored podataka ( letelica - upr. jed. )

\begin{tabular}{|c|c|c|c|c|c|c|c|}
\hline 0 & 1 & 2 & 3 & 4 & 5 & 6 & 7 \\
\hline \multicolumn{2}{|c|}{ Vbat } & Ibat & Hum & Temp & Press & Alt & non \\
\hline
\end{tabular}

Vbat - Napon baterije

Ibat - Struja baterije

Hum - Vlažnost vazduha

Temp - Temperatura

Press - Pritisak

Alt - Visina

Brzina prenosa podataka je na minimalnoj brzini od $250 \mathrm{kbps}$ čime se postiže maksimalan domet radio veze od $1.1 \mathrm{~km}$. Potrebno je naglasiti i da se kanal prenosa nalazi na 108 od 125 kako bi se nosač našao iznad frekvencije korišćenog nosača za bežičnu komunikaciju (eng. wireless) mreže kako se bi se izbegla interferencija sa drugim signalima u istom frekvencijskom spektru u toku prenosa.

\section{MOTORI}

Koriste se četri motora bez četkica (eng. brushless) i na njima se nalaze propeleri LjI 5045. Motori su pogonjeni ESC (eng. electronic speed control) EMAX BLHeli 30A. Komunikacioni protokol za upravljanje ESC-ovima koji se koristi je OneShot 125. Ovo predstavlja osam puta brži protokol od klasičnog PWM (eng. Pulse Width Modulation) protokola. Neophodnost korišćenja ovog prokokola je iz razloga što je potrebno da $P I D$ petlja a samim tim i upravljanje motorima bude veće od $250 \mathrm{~Hz}$ ovo nije moguće da klasičnim $P W M$-om koji radi na $50 \mathrm{~Hz}$. Sa OneShot 125 protokolom moguće je vršiti kontrolu motora i do osam puta brže. Specifičnost ovog protokola je da se širina impulsa menja od 125-250 $\mu$ S dok je perioda $2.5 \mathrm{mS}$. Na Slici 3 prikazan je signal datog protokola.

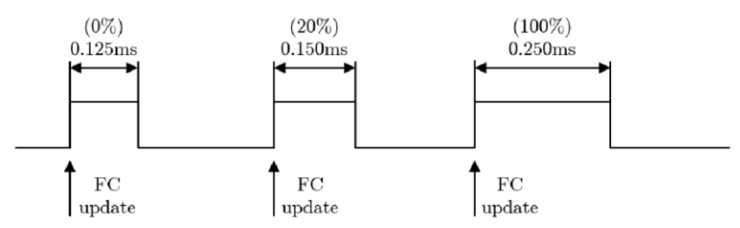

Slika 3. Protokol OneShot 125 [4]

Minimalna razlika koju ESC može da detektuje između trajanja impulsa je $1 \mu$ s tako da se zapravo postoji 125 različitih upravljačkih signala.

\section{HMI EKRAN}

Za prikaz informacija na upravljačkoj jedinici koristi se HMI (eng. Human-Machine Interface) Ekran (eng. display). Ovo predstavlja vrlo jednostavan način za prikaz informacija. $H M I$ sastoji se od ekrana osetljivog na dodir i kontrolera. Za programiranje interfejsa koristi se Nextion editor. Upravljanje ekranom vrši se asinhronom UART komunikacijom sa brzinom od 9600.

Prednost ovakve vrste prikaza je što već unapred postoje predefinisane funkcije za iscrtavanje grafika, dodavanje dugmadi, tekstova itd. Korišćeni ekran je veličine 2.8".

\section{SENZOR BME280}

Za određivanje osnovnih parametara vazduha u kom se nalazi letelica koristi se senzor BME 280. Ovaj senzor ima mogućnost merenja temperature, pritiska i vlažnosti vazduha. Ima vrlo oseljiv senzor pritiska pa je moguće odrediti nadmorsku visinu u odnosu na pritisak.

Matematička jednačina koja povezuje pritisak sa nadmorskom visinom data je u nastavku :

visina $=44330 \cdot\left(1-\left(\frac{\text { pritisak }}{\text { pritisak_nivoa_mora }}\right)^{0.1903}\right)$

Jednačina 1. Određivanje nadmorske visine [5]

Najveća nadmorska visina ostvarena pri letu ostaje zabeležena i može se očitati na ekranu upravljačke jedinice. Kao i ostali podaci obezbeđeni od strane ovog senzora.

\section{MERENJE STRUJE I NAPONA}

Merenje struje koja se povlači iz baterije meri se uz pomoć ACS758. Ovo je senzor koji meri magnetno polje koje proizvodi kretanje struje kroz provodnik. Senzor je baziran na hall-ovom efektu i odlikuje ga veoma niska otpornost okvirno oko $100 \mathrm{u} \Omega$. Izlaz ovog senzora dovodi se na ulaz $A D S 1115$ integrisanog četorokanalnog $A D$ konvertora koji je podešen da meri napon u opsegu +4.096V. ADS1115 je 16-bitni $A D$ konvertor koji se koristi i za precizno merenje napona baterije. Kako se u projektu koristi 3S ( tri serijski vezane ćelije) li-po baterija maksimalnog izlaznog napona $12.6 \mathrm{~V}$, merenje je potrebno izvršiti preko naponskog razdelnika koji je sastavljen od otpornika tolerancije $1 \%$ otpornosti $1 \mathrm{k} 5 \Omega$ i $4 \mathrm{k} 7 \Omega$. Podaci o struji i naponu prikazuju se na ekranu upravljačke jedinice. Na slici 4 data je blok šema gore navedenog mernog sistema.

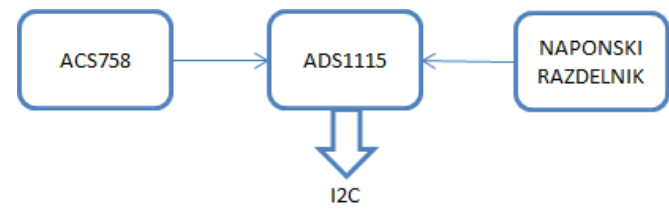

Slika 4. Blok šema mernog sistema na letelici

\section{REZULTATI}

Testiranja pokazuju da je dobijena funkcionalna letelica. Odmah nakon poletanja u vremenu od 200ms u mogućnosti je da uspostavi stabilnost. Za ovo je zaslužan ranije pomenut sistem za isključivanje iregulatora.

S obzirom na to da letelica nema regulator koji bi držao visinu fiksnom (eng. auto leveling) može se reći da je letelica prilično upravljiva i različite visine moguće je održavati menjanjem snaga motora. 
Odziv letelice koji je direktno zavisan od korišćenog komunikacionog modula radi veoma stabilno bez gubljenja poruka kada je između prijemnika i predajnika omogućena optička vidljivost i kada je njihovo rastojanje do $200 \mathrm{~m}$. Korišćenjem snažnijeg primo-predajnika sa većim dometom koji bi brže slao poruke postigao bi se upravljiviji sistem.

Merenje parametara vazduha temperature, vlaznosti i pritiska koji se dobijaju iz BME 280 senzora potrebno je testirati kako bi se potvrdili dobijeni rezultati i detektovala moguća odstupanja od tačnih vrednosti.

\section{ZAKLJUČAK}

U ovom radu predstavljen je jedan od načina implementacije letelice sa četiri motora sa vertikalnim potiskom, kvadkoptera. Implementirano rešenje zasniva se na algoritmu korišćenom u letelicama korišćenim za zabavu koji koriste veoma jeftine komponente (MPU6050, NRF24l01). Korišćenjem kvalitetnijih senzora položaja kvalitet upravljanja bi se zanatno poboljšao. Takođe, treba istaći da je ceo projekat zasnovan na STM32F103C8T6 jeftinom mikrokontroleru sa vrlo ograničenim mogućnostima.

Korišćenjem bržeg kontrolera omogućili bi povećanje brzine čitanja sa senzora položaja kao i povećanje brzine izračunavanja PID petlje. Ograničavajući faktor $u$ poboljšanju letelice jeste i sam OneShot 125 protokol koji ograničava upravljanje na $400 \mathrm{~Hz}$.

Za veće brzine potrebno je korisiti neki napredniji upravljački protokol kao što su OneShot42, Dshot, MultiShot koji predstavljaju mnogo brže protokole [6] Povećanje brzine i kvaliteta letenja podrazumeva i brisanje epiteta niskobudžetne letelice iz gore navedenih razloga.

\section{LITERATURA}

[1] https://i.stack.imgur.com/4fA1L.png (pristupljeno u oktobru 2019.)

[2] http://www.brokking.net/ymfc-al_main.html (pristupljeno u oktobru 2019.)

[3] M. F. Silva et al., "Design of angular PID controllers for quadcopters built with low cost equipment," 2016 20th International Conference on System Theory, Control and Computing (ICSTCC), Sinaia, 2016

[4] https://www.researchgate.net/figure/An-example-ofthe-PWM-signal-under-the-OneShot125protocol_fig12_327417180 (pristupljeno u oktobru 2019.)

[5] W. Zhu, Y. Dong, G. Wang, Z. Qiao and F. Gao, "High-precision barometric altitude measurement method and technology," 2013 IEEE International Conference on Information and Automation (ICIA), Yinchuan, 2013

[6] https://quadmeup.com/pwm-oneshot125-oneshot42and-multishot-comparison/ (pristupljeno u oktobru 2019.)

\section{Kratka biografija:}

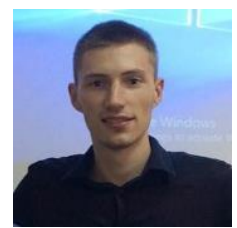

Milan Božić rođen je u Rumi 1995. god. Osnovnu školu "Dositej Obradović" završio je 2010.godine u Putincima. Tehničku školu "Milenko Brzak - Uča" u Rumi završio je 2014.godine. Diplomski rad na Fakultetu tehničkih nauka iz oblasti Elektrotehnike i računarstva Primenjena elektronika odbranio je 2018.god.

kontakt: milan.bozic@uns.ac.rs 